\title{
Prognostic Relevance of Nonsustained Ventricular Tachycardia in Patients with Pulmonary Hypertension
}

\author{
Dirk Bandorski, ${ }^{1}$ Harilaos Bogossian, ${ }^{2}$ Johanna Stempfl, ${ }^{1}$ Werner Seeger, ${ }^{1}$ \\ Matthias Hecker, ${ }^{1}$ Ardeschir Ghofrani, ${ }^{1}$ Reinhard Hoeltgen, ${ }^{3}$ and Henning Gall ${ }^{1}$ \\ ${ }^{1}$ University of Giessen and Marburg Lung Center (UGMLC), The German Center for Lung Research (DZL), Klinikstrasse 33, \\ 35392 Giessen, Germany \\ ${ }^{2}$ Klinikum Lüdenscheid, Universität Witten-Herdecke, Medizinische Klinik III, Paulmannhöherstr. 14, 58515 Lüdenscheid, Germany \\ ${ }^{3}$ Klinikum Westmünsterland, St. Agnes-Hospital Bocholt-Rhede, Medical Clinic 1-Cardiology/Electrophysiology, \\ Barloer Weg 125, 46397 Bocholt, Germany
}

Correspondence should be addressed to Dirk Bandorski; dirk.bandorski@hkw.med.uni-giessen.de

Received 18 September 2016; Accepted 23 November 2016

Academic Editor: Ramazan Akdemir

Copyright (C) 2016 Dirk Bandorski et al. This is an open access article distributed under the Creative Commons Attribution License, which permits unrestricted use, distribution, and reproduction in any medium, provided the original work is properly cited.

Background. Increased pulmonary vascular resistance in patients with pulmonary hypertension $(\mathrm{PH})$ leads to an increased afterload of right heart and cardiac remodeling which could provide the substrate or trigger for arrhythmias. Supraventricular arrhythmias were associated with clinical deterioration but were not associated with sudden cardiac death (SCD). SCD has been reported to account for approximately $30 \%$ of deaths in patients with pulmonary arterial hypertension (PAH). Objective. The role of nonsustained ventricular tachycardia (nsVT) and its prognostic relevance in patients with $\mathrm{PH}$ remains unclear. This study evaluated the prognostic relevance of nsVT in patients with PAH and chronic thromboembolic pulmonary hypertension (CTEPH). Methods. Retrospectively, patients with PAH and CTEPH who underwent Holter ECG monitoring and available data of survival were investigated. Results. Seventy-eight (PAH: 55, CTEPH: 23) patients were evaluated. Holter ECG revealed nsVT in 12 patients. Twenty-one patients died during follow-up. In patients with nsVT, tricuspid annular plane systolic excursion was lower $(p=0.001)$, and systolic pulmonary arterial pressure was higher $(p=0.163)$. Mean survival of patients without/with nsVT was 155.2 $\pm 8.5 / 146.4$ \pm 21.4 months $(p=0.690)$. The association between arrhythmias and survival was not confounded by age $(p=0.681)$, gender ( $p=0.752), 6-\mathrm{MW}$ distance $(p=0.196)$, or arterial hypertension $(p=0.238)$. Conclusions. In patients with PH, nsVT occurs more often than previously reported, and patients with $\mathrm{PH}$ group 1 seem to be more at risk.

\section{Introduction}

Pulmonary arterial hypertension (PAH) and chronic thromboembolic pulmonary hypertension (CTEPH) are characterized by progressive obliteration of precapillary pulmonary vessels leading to an increased pulmonary vascular resistance (PVR). The subsequent increase in PVR leads to an increased afterload of the right heart and cardiac remodeling [1]. Elevated right heart filling pressures and cardiac remodeling could provide the substrate or trigger for arrhythmias [2, 3]. Five studies evaluated the incidence of supraventricular arrhythmias in patients with $\mathrm{PH}$, which varied between $11.7 \%$ and $25.1 \%$ over periods of $6-13$ years [4-8]. Supraventricular arrhythmias were associated with clinical deterioration but were not associated with sudden cardiac death (SCD) [4-8]. SCD has been reported to account for approximately $30 \%$ of deaths in patients with PAH [9]. In our own data, $13 \%$ of the $\mathrm{PH}$ patients showed nonsustained ventricular tachycardia (nsVT) during Holter ECG monitoring [10]. Because of missing follow-ups in the study, the role of nonsustained ventricular tachycardia and its prognostic relevance in patients with $\mathrm{PH}$ remains unclear. The recent study was performed to evaluate the prognostic relevance of nsVT in patients with PAH and CTEPH. 


\section{Methods}

Retrospectively, patients with $\mathrm{PAH}$ and CTEPH from two previous studies $[10,11]$ who underwent Holter ECG monitoring (University of Giessen, Medical Clinic I and Medical Clinic 2 and Kerckhoff-Klinik, Department of Cardiology) and available data of survival on 2015.06 .30 were investigated. To match our results with other studies $[4-6,8]$, we investigated the survival rate in patients of $\mathrm{PH}$ groups 1 and 4. Data collection included demographic data, etiology of $\mathrm{PH}$, comorbidities, survival, cause of death, and data from echocardiography. Hemodynamic data from right heart catheterization were included if performed six months prior to Holter ECG monitoring. The study and the study design were approved by the institutional review board (reference number: 184/15).

\section{Holter ECG Monitoring}

For assessment of arrhythmias, all patients underwent Holter ECG recording (GETEMED, Teltow, Germany) for 24 [11] or 72 hours [10]. The recordings were analyzed by an operatorcontrolled analysis (GETEMED, Teltow, Germany). Classification of documented nsVT (three or more beats in duration, terminating spontaneously in less than $30 \mathrm{~s}$ ) was performed in accordance with the terminology of the American Society of Cardiology, American Heart Association, and European Society of Cardiology [12]. The results of the Holter ECG recordings were correlated with six-minute walk distance and data of echocardiography and right heart catheterization.

\section{Six-Minute Walk (6-MW) Testing}

Patients walked along a 100-foot floor at their own pace to cover as much distance as possible. The total accessible distance was determined. The tests were performed in accordance with the guidelines of the American Thoracic Society (ATS) [13].

\section{Echocardiography}

Transthoracic echocardiographic studies were performed by experienced investigators (GE, Connecticut, USA). Collected data contained right atrial (RA) diameter (four-chamber view, measured at the end systole), right ventricle (RV) diameter (four-chamber view, measured at the end diastole), left ventricular ejection fraction (LV-EF, biplane Simpson method, two- and four-chamber view), tricuspid annular plane systolic excursion (TAPSE), and systolic pulmonary artery pressure (sPAP). All measurements were carried out in accordance with the guidelines of the American Society of Echocardiography [14-17].

\section{Right Heart Catheterization}

Right heart catheterization was performed via the right jugular vein. The hemodynamic measurements included mean right atrial pressure (RAP), mean pulmonary pressure (mPAP), pulmonary capillary wedge pressure (PCWP), pulmonary vascular resistance (PVR), and cardiac index (CI, thermodilution or Fick method, as appropriate).

\section{Statistical Analysis}

Statistical calculations were performed using SPSS (ver. 21; IBM, Armonk, NY). Patient data are presented as absolute numbers (mean or median) and standard deviations (SDs). Comparisons between groups were done using $t$-test or chisquare test as appropriate. $p$ values of $<0.05$ were considered statistically significant.

Cox regression analyses were performed to evaluate the influence of nsVT on survival. Multivariate Cox regression was used to adjust for possible confounders, namely, age, sixminute walk distance (6-MWD), echocardiographic parameters (sPAP, diameter of RA/RV, TAPSE, and LV-EF), and hemodynamic parameters (RAP, PVR, PCWP, mPAP, CI, and ven $\mathrm{sO} 2)$.

Kaplan-Meier plots were used to illustrate survival in relation to ventricular tachycardia. Statistical analyses were performed using data obtained during the entire observation period (up to 200 months).

\section{Results}

A total of 78 patients were evaluated: 55 with $\mathrm{PAH}$ and 23 with CTEPH (7 patients suffered from persistent CTEPH after pulmonary artery embolectomy and 16 patients declined pulmonary embolectomy). Holter ECG revealed nsVT in 12 patients (PAH: 8 patients; CTEPH: 4 patients). Patients walked $370 \pm 125 \mathrm{~m}$ in six minutes (patients without nsVT: $387 \pm 281 \mathrm{~m}$; patients with nsVT: $283 \pm 109 ; p=0.941)$. General characteristics are presented in Table 1.

Mean time from first diagnosis of PH to Holter ECG was $5.4 \pm 3.9$ years for patients without nsVT and $6.2 \pm 4.1$ years for patients with nsVT $(p=0.736)$. In patients with PAH, the mean interval between first diagnosis of $\mathrm{PH}$ and Holter ECG was $5.5 \pm 4.1$ years and $5.7 \pm 3.7$ years in patients with CTEPH $(p=0.496)$. Twenty-one patients [26.9\%, 17 patients without nsVT (PH group $1+4)$ and 4 patients with nsVT $(\mathrm{PH}$ group 1)] died during follow-up, caused by right heart failure in 7 patients, sudden cardiac death in 6 patients, respiratory insufficiency in 2 patients, and decompensated aortic valve stenosis in 1 patient, and in 5 patients the cause of death was unknown. In the subgroup of patients with nsVT, causes of death were right heart failure in 2 patients, sudden cardiac death in 1 patient, and decompensated aortic valve stenosis in 1 patient. The mean interval from first diagnosis to death was $8.4 \pm 3.9$ years in patients without nsVT and $7.9 \pm 3.5$ years in patients with nsVT $(p=0.185)$. The average interval from first diagnosis to death was $8.2 \pm 3.9$ years in patients with $\mathrm{PAH}$ and $8.5 \pm 3.8$ years in patients with CTEPH $(p=0.855)$.

\section{ECG Parameters}

Neither in patients with or without arrhythmia nor between survivors' and nonsurvivors' heart rate did mean QRS width, QT interval, and corrected QT interval (QTc) show any 
TABLE 1: Baseline characteristics.

\begin{tabular}{|c|c|c|c|}
\hline & $\begin{array}{l}\text { Patients without nsVT } \\
\qquad(n=66)\end{array}$ & $\begin{array}{l}\text { Patients with nsVT } \\
\qquad(n=12)\end{array}$ & $\begin{array}{c}\text { Significance } \\
p \\
\end{array}$ \\
\hline Diagnosis (PH group 1/4) & $47 / 19$ & $8 / 4$ & 0.277 \\
\hline Age (years) & $\begin{array}{c}60 \pm 14.7 \\
\text { (Median: 60.5) }\end{array}$ & $\begin{array}{c}66.6 \pm 12.4 \\
\text { (Median: } 66)\end{array}$ & 0.112 \\
\hline Gender (female/male) & $50 / 16$ & $8 / 4$ & 0.277 \\
\hline $\begin{array}{l}\text { PAH-specific medication } \\
\text { (PDE5i/ERA/inh } \\
\text { Prostanoid/CCB/Ima) }\end{array}$ & $28 / 7 / 0 / 5 / 2$ & $5 / 2 / 0 / 1 / 0$ & \\
\hline Combination therapy (dual/triple) & $\begin{array}{c}\text { PDE5i }+ \text { ERA }=15, \\
\text { PDE5i }+ \text { inh Prostanoid }=3, \\
\text { PDE5i }+ \text { ERA }+ \text { inh Prostanoid }=4, \\
\text { PDE5i }+ \text { Ima }=2\end{array}$ & $\begin{array}{c}\text { PDE5i }+ \text { ERA = 2, } \\
\text { PDE5i }+ \text { inh Prostanoid }=2\end{array}$ & \\
\hline $\begin{array}{l}\text { Antiarrhythmic medication } \\
\text { (BB/Digoxin) }\end{array}$ & $11 / 1$ & $1 / 0$ & \\
\hline $\begin{array}{l}\text { Angiotensin-converting enzyme } \\
\text { inhibitors }\end{array}$ & 14 & 3 & \\
\hline Coronary heart disease & 8 & 2 & 0.274 \\
\hline Arterial hypertension & 28 & 7 & 0.238 \\
\hline Diabetes mellitus & 12 & 4 & 0.261 \\
\hline Cardiac pacemaker & 0 & 1 (indication: bradyarrhythmia) & \\
\hline
\end{tabular}

BB: beta blocker; CCB: calcium channel blocker; ERA: endothelin receptor antagonist; Ima: imatinib; inh Prostanoid: inhaled Prostanoid; $n$ : number; PDE5i: phosphodiesterase-5 inhibitor; PH: pulmonary hypertension; nsVT: nonsustained ventricular tachycardia.

TABLE 2: ECG parameters.

\begin{tabular}{|c|c|c|c|c|c|c|c|c|}
\hline & $\begin{array}{l}\text { Heart rate } \\
\text { (beats/min) }\end{array}$ & $p$ & $\begin{array}{l}\text { QRS width } \\
\text { (ms) }\end{array}$ & $p$ & $\begin{array}{l}\text { QT interval } \\
(\mathrm{ms})\end{array}$ & $p$ & $\begin{array}{c}\text { Corrected QT } \\
\text { interval } \\
(\mathrm{ms}) \\
\end{array}$ & $p$ \\
\hline \multicolumn{9}{|l|}{ Survival } \\
\hline yes $(n=57)$ & $74 \pm 13$ & \multirow{2}{*}{0.823} & $93 \pm 13$ & \multirow{2}{*}{0.350} & $392 \pm 31$ & \multirow{2}{*}{0.503} & $432 \pm 31$ & \multirow{2}{*}{0.291} \\
\hline no $(n=21)$ & $78 \pm 14$ & & $92 \pm 11$ & & $385 \pm 36$ & & $438 \pm 25$ & \\
\hline \multicolumn{9}{|l|}{ Arrhythmia } \\
\hline yes $(n=12)$ & $76 \pm 16$ & \multirow{2}{*}{0.870} & $93 \pm 8$ & \multirow{2}{*}{0.195} & $393 \pm 32$ & \multirow{2}{*}{0.905} & $441 \pm 34$ & \multirow{2}{*}{0.47} \\
\hline no $(n=66)$ & $74 \pm 13$ & & $92 \pm 13$ & & $389 \pm 33$ & & $433 \pm 29$ & \\
\hline
\end{tabular}

min: minute; ms: milliseconds; $n$ : number; SD: standard deviation.

statistical significance. Mean QTc in patients with nsVT who died during follow-up was $445 \mathrm{~ms}$ (data not shown).

\section{Echocardiography and Right Heart Catheterization}

Cardiac function and hemodynamic parameters were evaluated by echocardiography and right heart catheterization. Echocardiography was performed in all patients, and data of right heart catheterization within the last 6 months before Holter ECG monitoring were available in 49 patients (40/66 patients without nsVT and 9/12 patients with nsVT). TAPSE was significantly lower in patients with nsVT $(p=0.001)$, and sPAP was higher in patients with nsVT $(p=0.163)$. Right heart catheterization revealed higher $\operatorname{mPAP}(p=0.865)$ and $\operatorname{PVR}(p=0.353)$ and lower CI $(p=0.390)$ in patients with nsVT. Echocardiography showed normal LV-EF in 77 patients and low reduction in one patient (no coronary heart disease, TAPSE $14 \mathrm{~mm}$ ) with nsVT and CTEPH (not shown in Table 2). Diameter of the right atrium was larger (48.3 versus $43 \mathrm{~mm} ; p=0.013)$, TAPSE was lower (13.7 versus $16.7 \mathrm{~mm}$; $p=0.005)$, and CI was similar (2.57 versus $2.411 / \mathrm{min} / \mathrm{m}^{2}$; $p=0.010)$ in patients with nsVT who died during follow-up (data not shown).

\section{Survival and Arrhythmias}

Mean survival of patients without/with nsVT (Figure 1) was $155.2 \pm 8.5 / 146.4 \pm 21.4$ months without statistical significance $(p=0.690)$. Multivariate analysis revealed that the association between arrhythmias and survival was not confounded by age $(p=0.681)$, gender $(p=0.752), 6-\mathrm{MW}$ distance $(p=0.196)$, or arterial hypertension $(p=0.238)$. 


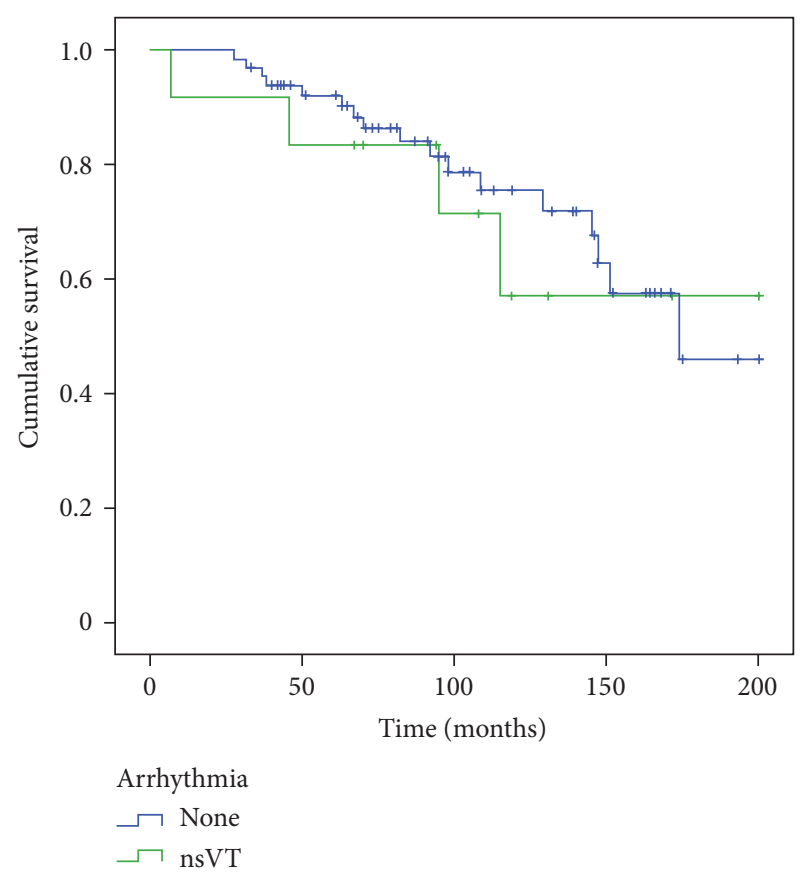

FIGURE 1: Nonsustained ventricular tachycardia and survival. nsVT: nonsustained ventricular tachycardia.

\section{Discussion}

Investigations analyzing the prognostic relevance of nsVT in patients with pulmonary hypertension are lacking. Only three studies report on ventricular arrhythmia during 2472-hour Holter ECG [10, 11, 18], but none of these studies report on the prognostic relevance of nonsustained VT. We retrospectively analyzed our data to discover the prognostic relevance of $\mathrm{nsVT}$, as none of the mentioned studies revealed any respective information. To match our results with other studies $[4-6,8]$, we investigated survival in patients $(n=$ 78) of $\mathrm{PH}$ groups 1 and 4 . Our data showed no significant difference of survival in patients with and without nsVT (7.9 \pm 3.5 years versus $8.4 \pm 3.9$ years; $p=0.185$ ). Mean times from diagnosis to Holter ECG were similar for both groups (with/without nsVT: $6.2 \pm 4.1$ years versus $5.4 \pm 3.9$ years; $p=0.736$ ), indicating that the duration of $\mathrm{PH}$ does not seem to influence the probability of nsVT.

Nonsustained VT can be recorded in a wide range of different conditions, from apparently healthy individuals to patients with significant left heart disease. Its prognostic significance varies, depending on the underlying conditions (ischemic heart disease, cardiomyopathies, etc.) [19]. Depending on underlying diseases, antiarrhythmic therapy is recommended [19]. In contrast to patients with left heart disease, ventricular arrhythmias in patients with pulmonary hypertension are reported to be rare. The prognostic relevance of nsVT in patients with $\mathrm{PH}$ remains unclear. No trials to investigate the indications for antiarrhythmic therapy have been conducted in patients with $\mathrm{PAH}$, and the ACC/AHA/ESC guidelines do not recommend prophylactic antiarrhythmic therapy in patients with $\mathrm{PH}$ either [12]. Two studies report sudden cardiac death (SCD) as the reason for about $30 \%$ of deaths in patients with pulmonary arterial hypertension, and SCD appears more common in patients with primary PAH than in those with CTEPH $[20,21]$. In Hoeper's study, reporting the outcome after cardiopulmonary resuscitation, initial ECG presented ventricular fibrillation in only $8 \%$ of their patients. The other cases shared bradycardia (45\%), electromechanical dissociation (28\%), asystole (15\%), or other arrhythmias (4\%) [21].

Umar et al. evaluated the incidence of SCD in rats with $\mathrm{PH}$ induced by subcutaneous injection of monocrotaline [3]. Right ventricular ejection fraction deteriorated between the 14 th day and 21 st day after injection from 72 to $38 \%$. The highest incidence of SCD occurred between days 23 and 32. Early afterdepolarizations (EADs) from the right ventricular epicardial surface triggered VT, which degenerated to ventricular fibrillation [3]. Two underlying mechanisms maintaining ventricular arrhythmias were identified by the authors: focal and incomplete reentrant wave fronts during ventricular fibrillation. The drop of the RV-EF occurred 10 days before the rise of SCD in the MCT-treated rats, and therefore the authors concluded that electric failure rather than hemodynamic deterioration was the reason for ventricular fibrillation. It is well known that EADs in humans can trigger malignant arrhythmias as torsade de pointes [22]. Theoretical and experimental studies identified reduced repolarization reserve, increased myocardial fibrosis, and elevated cytosolic Ca levels that promote EADs as mechanisms triggering tachyarrhythmias [23-28]. Cardiac MRI revealing delayed contrast enhancement $[29,30]$ and newly technical innovations like myocardial T1 mapping [31] might be helpful in identifying patients with cardiac fibrosis.

Echocardiographic and hemodynamic data such as sPAP, TAPSE, PVR, mPAP, CI, ven $\mathrm{sO}_{2}$, and $\mathrm{RA} / \mathrm{RV}$ diameter were in accordance with the studies of Olsson et al. [4] and Wen et al. [8], investigating $\mathrm{PH}$ patients (PAH and $\mathrm{CTEPH})$ with and without supraventricular arrhythmias. The studies revealed elevated sPAP, mPAP, and RA/RV diameters and reduced $\mathrm{CI}$, ven $\mathrm{sO}_{2}$, and TAPSE in patients with supraventricular arrhythmias $[4,8]$. The prognostic value of TAPSE was evaluated in three studies by Forfia et al. and Ghio et al. [32-34]. The study of Forfia et al. revealed that the survival of patients with a TAPSE less than 1.8 was significantly shorter than that of patients with a TAPSE of $1.8 \mathrm{~cm}$ or greater [32]. In Ghio's first study, TAPSE $<15 \mathrm{~mm}$ was strictly related to prognosis, and patients with TAPSE $\leq 15 \mathrm{~mm}$ had a nearly threefold event rate compared to patients with TAPSE of $15 \mathrm{~mm}(\mathrm{HR}=2.74)$ [33]. The second study of Ghio et al. confirmed these results [34]. A TAPSE $\geq 15 \mathrm{~mm}$ at baseline/after therapy was associated with a significantly lower risk of death or clinical worsening [34].

Values of mPAP, sPAP, CI, PVR, and ven $\mathrm{sO}_{2}$ in these three studies (if recorded in the study) were similar to our patients with nsVT, whereas RAP $(8.5 / 10 \mathrm{mmHg}$ versus $4 \mathrm{mmHg}$ ), PCWP (10 $\mathrm{mmHg}$ versus $7.9 \mathrm{mmHg}$ ), diameter of RA (48 mm versus $46 \mathrm{~mm}$ ), and diameter of RV (46 mm versus $42 \mathrm{~mm}$ ) were lower in our patients.

In summary, in patients with nsVT during follow-up, hemodynamic parameters (mPAP, sPAP, CI, PVR, and ven 
TABLE 3: Echocardiographic and hemodynamic data.

\begin{tabular}{|c|c|c|c|c|}
\hline & All patients $(n=78)$ & Patients without nsVT $(n=66)$ & Patients with nsVT $(n=12)$ & $p$ value \\
\hline \multicolumn{5}{|l|}{ Echocardiography } \\
\hline RA diameter (mm) & 41.7 & 41.2 & 44.6 & 0.247 \\
\hline RV diameter (mm) & 38.9 & 38.4 & 41.8 & 0.197 \\
\hline sPAP (mmHg) & 63.3 & 61.6 & 72.7 & 0.163 \\
\hline TAPSE (mm) & 20.1 & 20.9 & 15.7 & 0.001 \\
\hline \multicolumn{5}{|c|}{ Right heart catheterization } \\
\hline mPAP (mmHg) & 40.8 & 40.2 & 47.7 & 0.865 \\
\hline RAP (mmHg) & 4.7 & 4.4 & 4.3 & 0.310 \\
\hline PCWP (mmHg) & 7.9 & 7.8 & 7.2 & 0.688 \\
\hline $\operatorname{PVR}\left(\right.$ dyn $\left.\cdot \mathrm{s} \cdot \mathrm{cm}^{-5}\right)$ & 563 & 532 & 835 & 0.353 \\
\hline $\mathrm{CI}\left(1 / \mathrm{min} / \mathrm{m}^{2}\right)$ & 2.73 & 2.81 & 2.42 & 0.390 \\
\hline ven $\mathrm{sO}_{2}(\%)$ & 67 & 68 & 64 & 0.700 \\
\hline
\end{tabular}

CI: cardiac index; cm: centimeter; dyn: Dyne; Hg: mercury; l: liter; m: meter; mm: millimeter; mPAP: mean pulmonary arterial pressure; $n$ : number; nsVT: nonsustained ventricular tachycardia; PCWP: pulmonary capillary wedge pressure; mPAP: mean pulmonary arterial pressure; PVR: pulmonary vascular resistance; RA: right atrium; RAP: right atrial pressure; RV: right ventricle; s: second; sPAP: systolic pulmonary arterial pressure; TAPSE: tricuspid annular plane systolic excursion; ven $\mathrm{sO}_{2}$ : venous oxygen saturation.

$\mathrm{sO}_{2}$ ) were similar to patients with supraventricular arrhythmias, whereas RAP was lower.

The prognostic value of QRS width and QT inter$\mathrm{val} /$ corrected QT interval was analyzed in three studies [3537]. Sun et al. analyzed QRS width in the initial 12-lead ECG in 212 patients with idiopathic $\mathrm{PH}$ [35]. The study revealed an increase of QRS width $\geq 0.12$ seconds, observed in $16.5 \%$ of patients, as an independent predictor of mortality, being associated with a 2.5 times higher risk of death. QRS prolongation was positively correlated with right atrium and right ventricle diameters, indicating that right ventricular overload may play a role in the pathogenesis of $\mathrm{PH}$. Hemodynamic variables were similar in the two groups (gp 1: QRS $<120 \mathrm{~ms}$ and gp 2: QRS $\geq 120 \mathrm{~ms}$ ): mRAP (gp 1: $7.4 \mathrm{mmHg} \pm$ 5.9; gp 2: $8.6 \mathrm{mmHg} \pm 7.8 ; p=0.30$ ), mPAP (gp 1: $61.1 \mathrm{mmHg} \pm 16.1$; gp 2: $60.9 \mathrm{mmHg} \pm 18.7 ; p=0.53$ ), and PVR (gp 1: 17 Wood units \pm 10.3; gp 2: 18.5 Wood units $\pm 9.8 ; p=0.69$ ). In our study, values (except ven $\mathrm{sO}_{2}$ ) of hemodynamic parameters were even lower than those of patients in group 1. RA diameter (gp 1: $59.6 \mathrm{~mm} \pm 11.0$; gp 2: $77.4 \mathrm{~mm} \pm 15.6$ ) was lower and RV diameter was higher (gp 1: $31.4 \mathrm{~mm} \pm 8.5$; gp 2: $38.6 \mathrm{~mm}$ \pm 9.4 ) than in our patients. Only 4 of our patients had a QRS width $>120 \mathrm{~ms}$.

Two studies compared the duration of the QTc intervals in patients with different types of $\mathrm{PH}$ and in controls [36, 37]. In Hong-Liang's study, the QTc interval was longer in patients with $\mathrm{PH}$ than in controls [severe $\mathrm{PH}$ (mean PAP $\geq 60 \mathrm{mmHg}$ ): $428.6 \mathrm{~ms} \pm 32.8$, mild-to-moderate $\mathrm{PH}$ (mean PAP $\geq 25 \mathrm{mmHg}$ and $<60 \mathrm{mmHg}$ ): $423.1 \mathrm{~ms} \pm 30.2$; controls: $411.1 \mathrm{~ms} \pm 28.4$ ] [36], and in Rich's study, the QTc interval was $454.8 \mathrm{~ms} \pm 29$ in patients with $\mathrm{PH}$ compared with $429 \mathrm{~ms} \pm 18$ in controls [37]. The duration of the QTc interval in patients with nsVT $(441 \mathrm{~ms} \pm 34)$ or those who died $(438 \mathrm{~ms} \pm 25)$ during follow-up was longer than in patients with severe $\mathrm{PH}$ (428.6 ms \pm 32.8 ) in Hong-Liang's study and showed values of QTc interval duration between the duration of patients with $\mathrm{PH}(454.8 \mathrm{~ms} \pm 29)$ and controls (429 ms \pm 18$)$ in Rich's study.
The mean QTc duration in our patients with nsVT who died during follow-up $(n=4)$ was $445 \mathrm{~ms} \pm 45$. The mean PAP of our patients (all patients, $40.8 \mathrm{mmHg}$ ) was lower than in the comparable group (patients with mild-to-moderate $\mathrm{PH}$ ) in Hong-Liang's study (47.3 mmHg) and lower than in Rich's study $(47.4 \mathrm{mmHg})$. In patients with nsVT, the values of mean PAP of Rich's, Hong-Liang's, and our patients were similar (about $47 \mathrm{mmHg}$ ). Compared with Rich's patients, PVR was lower in our patients (all patients, Table 3) but higher in patients with nsVT (835 versus $736 \mathrm{dyn} \mathrm{s} \mathrm{cm}^{-5}$ ). Hong-Liang did not provide these data [36].

By extending Holter ECG monitoring time up to $72 \mathrm{~h}$, the detection rate of patients with nsVT increased [10]. In three patients, nsVT was observed during the first $24 \mathrm{~h}$, in seven patients between 24 and $48 \mathrm{~h}$, and in two patients between 48 and $72 \mathrm{~h}$ of the recording. Additionally, as shown by Bass et al., prolongation of monitoring is useful and raises the number of detected arrhythmias [38].

On the whole, one-third of our patients with nsVT died during follow-up. Of course, the total number of patients in our trial is too low to draw statistically significant conclusions, but hemodynamic parameters and myocardial fibrosis, as discussed by Umar et al. and Rich et al. [3, 37], seem to be important for the development of arrhythmias in patients with $\mathrm{PH}$.

The limitations of the current study consist in the moderate sample size $(n=78)$ and the low number of patients with nsVT $(n=12)$. Basically, our study was not designed to understand the molecular substrates or investigate the mechanisms initiating nsVT observed in patients with $\mathrm{PH}$ in our previous studies.

\section{Conclusion}

In patients with $\mathrm{PH}$, nsVT occurs more often than previously reported, and patients with $\mathrm{PH}$ group 1 seem to be more at risk. Because of the moderate sample sizes, the prognostic 
relevance and risk factors for the development of nsVT in these patients cannot finally be assessed. Studies with a larger number of patients to obtain more information about the prognostic relevance of nsVT and risk factors (hemodynamic parameters and duration of QTc interval) for the development of nsVT are necessary. MRI can be useful for assessing myocardial fibrosis.

\section{Competing Interests}

The authors declare that there are no competing interests regarding the publication of this paper.

\section{Authors' Contributions}

Reinhard Hoeltgen and Henning Gall contributed equally to this article.

\section{References}

[1] L. J. Rubin, "Primary pulmonary hypertension," New England Journal of Medicine, vol. 336, no. 2, pp. 111-117, 1997.

[2] J.-K. Lee, I. Kodama, H. Honjo, T. Anno, K. Kamiya, and J. Toyama, "Stage-dependent changes in membrane currents in rats with monocrotaline-induced right ventricular hypertrophy," American Journal of Physiology-Heart and Circulatory Physiology, vol. 272, no. 6, pp. H2833-H2842, 1997.

[3] S. Umar, J.-H. Lee, E. De Lange et al., "Spontaneous ventricular fibrillation in right ventricular failure secondary to chronic pulmonary hypertension," Circulation: Arrhythmia and Electrophysiology, vol. 5, no. 1, pp. 181-190, 2012.

[4] K. M. Olsson, N. P. Nickel, J. Tongers, and M. M. Hoeper, "Atrial flutter and fibrillation in patients with pulmonary hypertension," International Journal of Cardiology, vol. 167, no. 5, pp. 2300-2305, 2013.

[5] J. Tongers, B. Schwerdtfeger, G. Klein et al., "Incidence and clinical relevance of supraventricular tachyarrhythmias in pulmonary hypertension," American Heart Journal, vol. 153, no. 1, pp. 127-132, 2007.

[6] M. J. Ruiz-Cano, A. Gonzalez-Mansilla, P. Escribano et al., "Clinical implications of supraventricular arrhythmias in patients with severe pulmonary arterial hypertension," International Journal of Cardiology, vol. 146, no. 1, pp. 105-106, 2011.

[7] D. Rottlaender, L. J. Motloch, D. Schmidt et al., "Clinical impact of atrial fibrillation in patients with pulmonary hypertension," PLoS ONE, vol. 7, no. 3, Article ID e33902, 2012.

[8] L. Wen, M.-L. Sun, P. An et al., "Frequency of supraventricular arrhythmias in patients with idiopathic pulmonary arterial hypertension," American Journal of Cardiology, vol. 114, no. 9, pp. 1420-1425, 2014.

[9] E. A. Demerouti, A. N. Manginas, G. D. Athanassopoulos, and G. T. Karatasakis, "Complications leading to sudden cardiac death in pulmonary arterial hypertension," Respiratory Care, vol. 58, no. 7, pp. 1246-1254, 2013.

[10] D. Bandorski, D. Erkapic, J. Stempfl et al., "Ventricular tachycardias in patients with pulmonary hypertension: an underestimated prevalence? A prospective clinical study," Herzschrittmachertherapie und Elektrophysiologie, vol. 26, no. 2, pp. 155-162, 2015.
[11] D. Bandorski, J. Schmitt, C. Kurzlechner et al., "Electrophysiological studies in patients with pulmonary hypertension: a retrospective investigation," BioMed Research International, vol. 2014, Article ID 617565, 6 pages, 2014.

[12] D. P. Zipes, A. J. Camm, M. Borggrefe et al., "ACC/AHA/ESC 2006 guidelines for management of patients with ventricular arrhythmias and the prevention of sudden cardiac death: a report of the American College of Cardiology/American Heart Association Task Force and the European Society of Cardiology Committee for Practice Guidelines (Writing Committee to Develop Guidelines for Management of Patients with Ventricular Arrhythmias and the Prevention of Sudden Cardiac Death): Developed in Collaboration with the European Heart Rhythm Association and the Heart Rhythm Society," Circulation, vol.114, no. 10, pp. e385-e484, 2006.

[13] R. O. Crapo, R. Casaburi, A. L. Coates et al., "ATS statement: guidelines for the six-minute walk test," American Journal of Respiratory and Critical Care Medicine, vol. 166, no. 1, pp. 111117, 2002.

[14] L. G. Rudski, W. W. Lai, J. Afilalo et al., "Guidelines for the Echocardiographic Assessment of the Right Heart in Adults: a report from the American Society of Echocardiography. Endorsed by the European Association of Echocardiography, a registered branch of the European Society of Cardiology, and the Canadian Society of Echocardiography," Journal of the American Society of Echocardiography, vol. 23, no. 7, pp. 685-713, 2010.

[15] R. M. Lang, M. Bierig, R. B. Devereux et al., "Recommendations for chamber quantification: a report from the American Society of Echocardiography's guidelines and standards committee and the Chamber Quantification Writing Group, developed in conjunction with the European Association of Echocardiography, a branch of the European Society of Cardiology," Journal of the American Society of Echocardiography, vol. 18, no. 12, pp. 14401463, 2005.

[16] H. Baumgartner, J. Hung, J. Bermejo et al., "Echocardiographic assessment of valve stenosis: EAE/ASE recommendations for clinical practice," European Journal of Echocardiography, vol. 10, no. 1, pp. 1-25, 2009.

[17] W. A. Zoghbi, M. Enriquez-Sarano, E. Foster et al., "Recommendations for evaluation of the severity of native valvular regurgitation with two-dimensional and Doppler echocardiography," Journal of the American Society of Echocardiography, vol. 16, no. 7, pp. 777-802, 2003.

[18] R. Sulica, P. Thiagarajah, S. Hanon et al., "Low prevalence of arrhythmias in patients with pulmonary arterial hypertension," American Journal of Respiratory and Critical Care Medicine, vol. 179, article A4902, 2009.

[19] D. G. Katritsis, W. Zareba, and A. J. Camm, "Nonsustained ventricular tachycardia," Journal of the American College of Cardiology, vol. 60, no. 20, pp. 1993-2004, 2012.

[20] J. Bjornsson and W. D. Edwards, "Primary pulmonary hypertension: a histopathologic study of 80 cases," Mayo Clinic Proceedings, vol. 60, no. 1, pp. 16-25, 1985.

[21] M. M. Hoeper, N. Galié, S. Murali et al., "Outcome after cardiopulmonary resuscitation in patients with pulmonary arterial hypertension," American Journal of Respiratory and Critical Care Medicine, vol. 165, no. 3, pp. 341-344, 2002.

[22] C. Antzelevitch and W. Shimizu, "Cellular mechanisms underlying the long QT syndrome," Current Opinion in Cardiology, vol. 17, no. 1, pp. 43-51, 2002. 
[23] N. Morita, A. A. Sovari, Y. Xie et al., "Increased susceptibility of aged hearts to ventricular fibrillation during oxidative stress," American Journal of Physiology-Heart and Circulatory Physiology, vol. 297, no. 5, pp. H1594-H1605, 2009.

[24] J. Saiz, J. M. Ferrero Jr., M. Monserrat, J. M. Ferrero, and N. $\mathrm{V}$. Thakor, "Influence of electrical coupling on early afterdepolarizations in ventricular myocytes," IEEE Transactions on Biomedical Engineering, vol. 46, no. 2, pp. 138-147, 1999.

[25] D. J. Huelsing, K. W. Spitzer, and A. E. Pollard, "Electrotonic suppression of early afterdepolarizations in isolated rabbit," American Journal of Physiology-Heart and Circulatory Physiology, vol. 279, no. 1, pp. H250-H259, 2000.

[26] L.-H. Xie, F. Chen, H. S. Karagueuzian, and J. N. Weiss, "Oxidative stress-induced afterdepolarizations and calmodulin kinase II signaling," Circulation Research, vol. 104, no. 1, pp. 79-86, 2009.

[27] Y. Xie, D. Sato, A. Garfinkel, Z. Qu, and J. N. Weiss, "So little source, so much sink: requirements for afterdepolarizations to propagate in tissue," Biophysical Journal, vol. 99, no. 5, pp. 1408$1415,2010$.

[28] D. Sato, L. H. Xie, A. A. Sovari et al., "Synchronization of chaotic early afterdepolarizations in the genesis of cardiac arrhythmias," Proceedings of the National Academy of Sciences of the United States of America, vol. 106, no. 9, pp. 2983-2988, 2009.

[29] R. J. Kim, D. S. Fieno, T. B. Parrish et al., "Relationship of MRI delayed contrast enhancement to irreversible injury, infarct age, and contractile function," Circulation, vol. 100, no. 19, pp. 19922002, 1999.

[30] R. J. Kim, E. Wu, A. Rafael et al., "The use of contrast-enhanced magnetic resonance imaging to identify reversible myocardial dysfunction," The New England Journal of Medicine, vol. 343, pp. 1445-1453, 2000.

[31] J. R. Burt, S. L. Zimmerman, I. R. Kamel, M. Halushka, and D. A. Bluemke, "Myocardial T1 mapping: techniques and potential applications," Radiographics, vol. 34, no. 2, pp. 377-395, 2014.

[32] P. R. Forfia, M. R. Fisher, S. C. Mathai et al., "Tricuspid annular displacement predicts survival in pulmonary hypertension," American Journal of Respiratory and Critical Care Medicine, vol. 174, no. 9, pp. 1034-1041, 2006.

[33] S. Ghio, C. Klersy, G. Magrini et al., "Prognostic relevance of the echocardiographic assessment of right ventricular function in patients with idiopathic pulmonary arterial hypertension," International Journal of Cardiology, vol. 140, no. 3, pp. 272-278, 2010.

[34] S. Ghio, S. Pica, C. Klersy et al., "Prognostic value of TAPSE after therapy optimisation in patients with pulmonary arterial hypertension is independent of the haemodynamic effects of therapy," Open Heart, vol. 3, no. 1, Article ID e000408, 2016.

[35] P.-Y. Sun, X. Jiang, M. Gomberg-Maitland et al., "Prolonged QRS duration: a new predictor of adverse outcome in idiopathic pulmonary arterial hypertension," Chest, vol. 141, no. 2, pp. 374380, 2012.

[36] Z. Hong-Liang, L. Qin, L. Zhi-Hong et al., "Heart rate-corrected QT interval and QT dispersion in patients with pulmonary hypertension," Wiener Klinische Wochenschrift, vol. 121, no. 910, pp. 330-333, 2009.

[37] J. D. Rich, T. Thenappan, B. Freed et al., "QTc prolongation is associated with impaired right ventricular function and predicts mortality in pulmonary hypertension," International Journal of Cardiology, vol. 167, no. 3, pp. 669-676, 2013.
[38] E. B. Bass, E. I. Curtiss, V. C. Arena et al., "The duration of Holter monitoring in patients with syncope. Is 24 hours enough?" Archives of Internal Medicine, vol. 150, no. 5, pp. 1073-1078, 1990. 


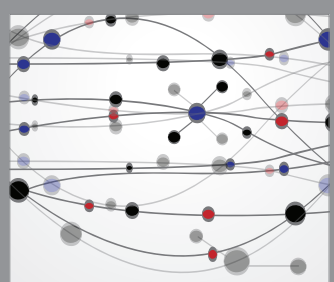

The Scientific World Journal
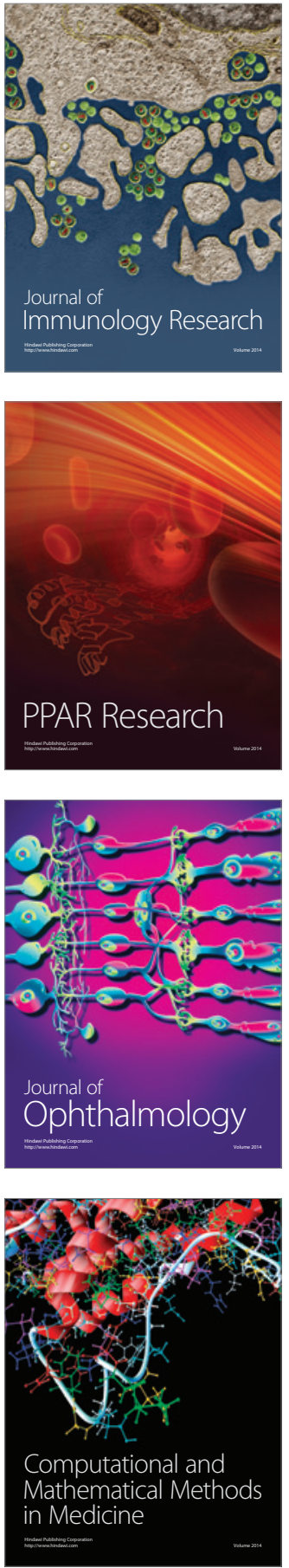

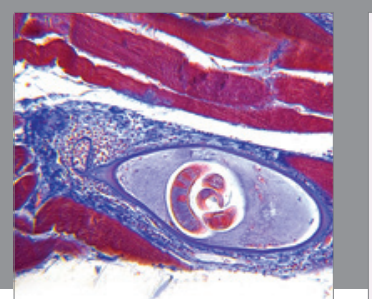

Gastroenterology Research and Practice

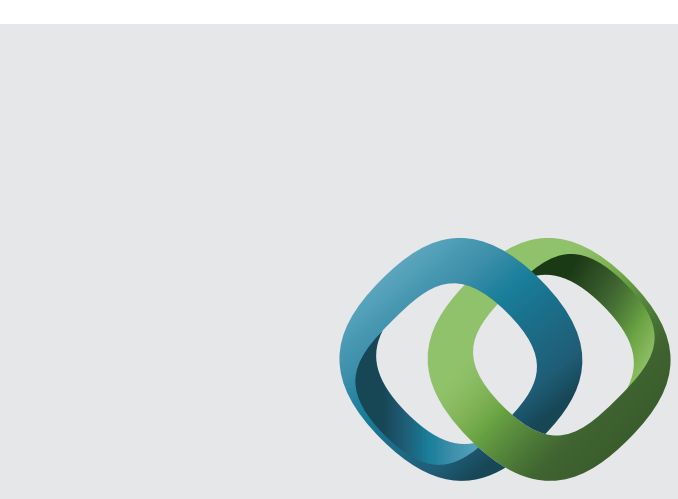

\section{Hindawi}

Submit your manuscripts at

http://www.hindawi.com
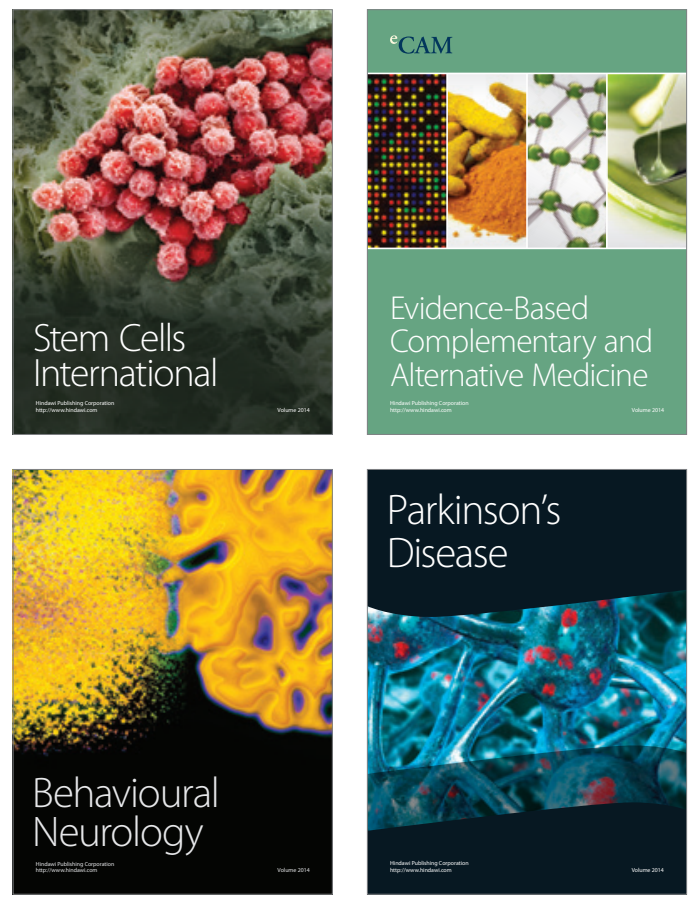
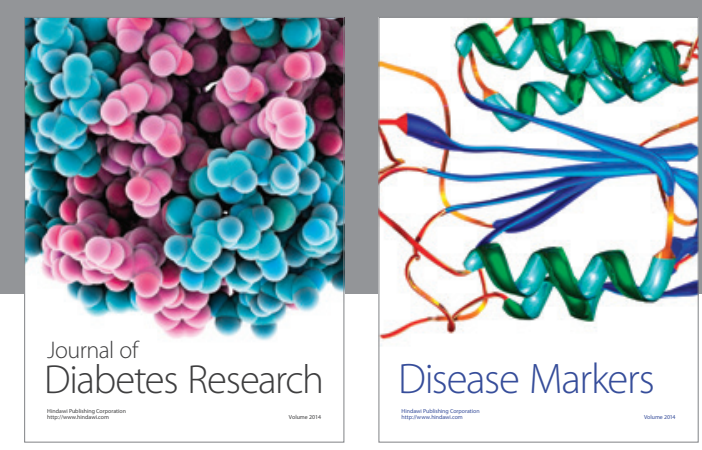

Disease Markers
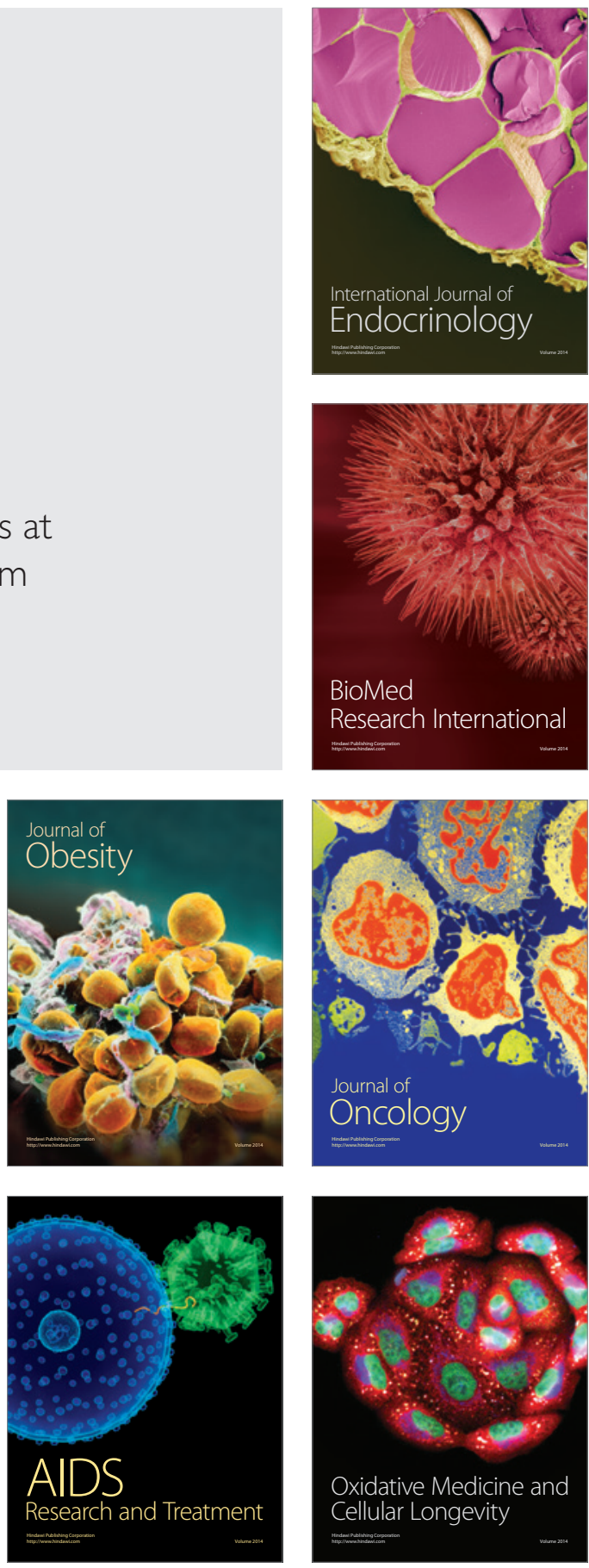